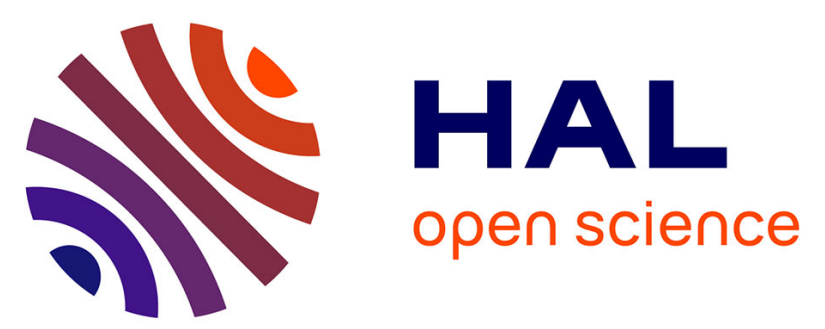

\title{
Incorporation of diet information derived from Bayesian stable isotope mixing models into mass-balanced marine ecosystem models: A case study from the Marennes-Oléron Estuary, France
}

Stephen Pacella, Benoit Lebreton, Pierre Richard, Donald Phillips, Theodore Dewitt, Nathalie Niquil

\section{To cite this version:}

Stephen Pacella, Benoit Lebreton, Pierre Richard, Donald Phillips, Theodore Dewitt, et al.. Incorporation of diet information derived from Bayesian stable isotope mixing models into mass-balanced marine ecosystem models: A case study from the Marennes-Oléron Estuary, France. Ecological Modelling, 2013, 267, pp.127 - 137. 10.1016/j.ecolmodel.2013.07.018 . hal-01087388

\author{
HAL Id: hal-01087388 \\ https://hal.science/hal-01087388
}

Submitted on 26 Nov 2014

HAL is a multi-disciplinary open access archive for the deposit and dissemination of scientific research documents, whether they are published or not. The documents may come from teaching and research institutions in France or abroad, or from public or private research centers.
L'archive ouverte pluridisciplinaire HAL, est destinée au dépôt et à la diffusion de documents scientifiques de niveau recherche, publiés ou non, émanant des établissements d'enseignement et de recherche français ou étrangers, des laboratoires publics ou privés. 
Incorporation of diet information derived from Bayesian stable isotope mixing models into mass-balanced marine ecosystem models: A case study from the Marennes-Oléron Estuary, France

Stephen PACELLA ${ }^{1,2^{*}}$, Benoit LEBRETON ${ }^{3}$, Pierre RICHARD ${ }^{3}$, Donald PHILLIPS ${ }^{2}$, Theodore DEWITT ${ }^{2}$, Nathalie NIQUIL ${ }^{3}$

${ }^{1}$ College of Earth, Ocean, and Atmospheric Sciences, Oregon State University, 104

Wilkinson Hall, Corvallis, OR, 97331, USA

${ }^{2}$ Western Ecology Division, Office of Research and Development, National Health and Environmental Effects Research Laboratory, United States Environmental Protection Agency, 200 SW $35^{\text {th }}$ Street, Corvallis, OR, 97333

${ }^{3}$ Université de la Rochelle-CNRS, UMR 6250, Littoral Environnement et Sociétés (LIENSs), 2 rue Olympe de Gouges, F-17000 La Rochelle, France

*corresponding author: spacella@ coas.oregonstate.edu, 1-412-952-2568 


\section{ABSTRACT}

We investigated the use of output from Bayesian stable isotope mixing models as constraints for a linear inverse food web model of a temperate intertidal seagrass system in the Marennes-Oléron Bay, France. Linear inverse modeling (LIM) is a technique that estimates a complete network of flows in an under-determined system using a combination of site-specific data and relevant literature data. This estimation of complete flow networks of food webs in marine ecosystems is becoming more recognized for its utility in understanding ecosystem functioning. However, diets and consumption rates of organisms are often difficult or impossible to accurately and reliably measure in the field, resulting in a large amount of uncertainty in the magnitude of consumption flows and resource partitioning in ecosystems. In order to address this issue, this study utilized stable isotope data to help aid in estimating these unknown flows. $\delta^{13} \mathrm{C}$ and $\delta^{15} \mathrm{~N}$ isotope data of consumers and producers in the Marennes-Oléron seagrass system was used in Bayesian mixing models. The output of these mixing models was then translated as inequality constraints (minimum and maximum of relative diet contributions) into an inverse analysis model of the seagrass ecosystem. We hypothesized that incorporating the diet information gained from the stable isotope mixing models would result in a more constrained food web model. In order to test this, two inverse food web models were built to track the flow of carbon through the seagrass food web on an annual basis, with units of $\mathrm{mg} \mathrm{C} \mathrm{m}^{-2} \mathrm{~d}^{-1}$. The first model (Traditional LIM) included all available data, with the exception of the diet constraints formed from the stable isotope mixing models. The second model (Isotope LIM) was identical to the Traditional LIM, but included the SIAR diet constraints. Both models were identical in structure, and intended to model the same 
Marennes-Oléron intertidal seagrass bed. Each model consisted of 27 compartments (24 living, 3 detrital) and 175 flows. Comparisons between the outputs of the models showed the addition of the SIAR-derived isotopic diet constraints further constrained the solution range of all food web flows on average by $26 \%$. Flows that were directly affected by an isotopic diet constraint were $45 \%$ further constrained on average. These results confirmed our hypothesis that incorporation of the isotope information would result in a more constrained food web model, and demonstrated the benefit of utilizing multi-tracer stable isotope information in ecosystem models.

\section{Keywords: Ecological model; Stable isotope; Inverse analysis; Food web; Seagrass}

\section{INTRODUCTION}

Current ecological questions are often complex in nature, requiring a holistic perspective in order to adequately address the multitude of variables and relationships. There is thus an ever-increasing pressure on ecologists to address these questions at the ecosystem scale. Quantitative food web models, representing partial or whole ecosystem flux networks, are a promising methodology to address ecological questions (Christian et al., 2009; Leslie and McLeod, 2007). These models are able to simultaneously explore effects of environmental changes on ecosystem structure and function, as well as emergent properties such as system dependencies, recycling, and efficiencies (Niquil et al., 2012). Banašek-Richter et al. (2004) showed that ecosystem descriptors based on quantified systems models are more accurate than their qualitative counterparts.

Estimation of complete flux networks of food webs in marine ecosystems is recognized 
for its utility to understand ecosystem functioning (Niquil et al., 2012). However, many components of ecosystem models are understood conceptually, but difficult or impossible to measure in the field, and therefore must be estimated (Niquil et al., 1998; van Oevelen et al., 2010; Vezina and Platt, 1988).

Inverse analysis is a powerful quantitative modeling method for estimating unmeasured components in ecosystem structures (Legendre and Niquil, 2012) and has been widely used for this reason in food web modeling (Breed et al., 2004; Daniels et al., 2006; Degré et al., 2006; Donali et al., 1999; Eldridge et al., 2005; Eldridge and Jackson, 1993; Grami et al., 2008; 2011; Jackson and Eldridge, 1992; Kones et al., 2009; Leguerrier et al., 2007; 2003; Niquil et al., 1998; 2006). It has become commonly referred to as Linear Inverse Modeling (LIM). Similarly to ECOPATH with ECOSIM (Christensen and Pauly, 1992; Pauly, 2000; Walters et al., 1997), LIM produces a static, mass-balanced, temporally integrated snapshot of the complete food web. Recent methodological advances have resulted in moving from models being solved with a single objective function (frequently a minimization function, (Vezina and Platt, 1988); Legendre and Niquil, 2012), to utilizing stochastic Markov Chain Monte Carlo methods to produce probability distributions of model results (LIM-MCMC) (Kones et al., 2009; 2006; Van den Meersche et al., 2009; van Oevelen et al., 2010). This technique avoids underestimates in both the size and complexity of the modeled food web as a result of the parsimony principle (Johnson et al., 2009; Kones et al., 2006). A more thorough review on the subject is covered by Niquil et al. (2012). Few applied studies have made use of recent methodological advances in this field, despite the relevance to informing 
conservation and environmental management decisions (Christian et al., 2009); Jorgensen 2007).

Stable isotopes are commonly used to study trophodynamics in ecosystems. Stable isotope analyses allow determination of food sources actually assimilated in the tissues of consumers over time, properly reflecting their trophodynamics depending on food source availability (Fry, 2006). Consumption rates are often difficult or impossible to accurately measure in the field, especially for smaller organisms, resulting in a large uncertainty in the magnitude of consumption flows and trophic resource partitioning in ecosystem models. Stable isotope data can be utilized to estimate these unmeasured flows (Navarro et al., 2011; van Oevelen et al., 2010). While the use of stable isotopes in diet studies has become standard practice (Moore and Semmens, 2008; Post, 2002), the integration of stable isotope data with whole food web network models has not been utilized frequently (Baeta et al., 2011; Navarro et al., 2011). The merits of this technique have been discussed recently in the literature (Navarro et al., 2011; van Oevelen et al., 2010).

Until now, only one stable isotopic marker $\left(\delta^{13} \mathrm{C}\right.$ or $\left.\delta^{15} \mathrm{~N}\right)$ at a time has been incorporated into inverse analysis models (Eldridge et al., 2005; Jackson and Eldridge, 1992; Oevelen et al., 2010; van Oevelen et al., 2006). Using two or more isotopic markers significantly increases model structure complexity and greatly increases model run time. This problem is compounded in situations where Monte Carlo methods are used to run the inverse analysis thousands of times (Kones et al., 2009; Niquil et al., 2012; van Oevelen et al., 2010). This has significant implications when attempting to 
add stable isotope information into food web models solved using the new Linear Inverse Model-Markov Chain Monte Carlo techniques (Kones et al., 2009; Niquil et al., 2012).

Therefore, the goal of this study was to find a way to incorporate information

from multiple stable isotope elements (i.e., ${ }^{13} \mathrm{C},{ }^{15} \mathrm{~N}$, etc.) into food web models using the LIM-MCMC technique, with minimum added complexity. In order to do this, we used the R package SIAR (Parnell et al., 2010) to analyze Bayesian mixing models using $\delta^{13} \mathrm{C}$ and $\delta^{15} \mathrm{~N}$ data to estimate food source distributions of the compartments in an inverse food web model of an intertidal seagrass bed. This information was then integrated into the LIM-MCMC food web model. Results of this model were compared with a corresponding model of the same system that excluded the isotope information obtained with the SIAR mixing models. We hypothesized that incorporating the food source information gained from the stable isotope information into the LIM-MCMC model would result in a significantly more constrained food web model, with reduced uncertainty associated with each flow.

\section{METHODS}

\subsection{Marennes-Oléron Bay study site and model data}

The seagrass system studied was an intertial Zostera noltii meadow located in Marennes-Oléron Bay, on the Atlantic coast of France $\left(45^{\circ} 54^{\prime} \mathrm{N}, 1^{\circ} 12^{\prime} \mathrm{W}\right)$ (Figure 1). This is a semi-enclosed, macrotidal bay, which receives freshwater inputs from the Charente River (15-500 $\left.\mathrm{m}^{3} \mathrm{~s}^{-1}\right)$ (Ravail-Legrand et al., 1988). The seagrass bed studied extends for $15 \mathrm{~km}$ along the eastern shore of Oléron Island, and is $1.5 \mathrm{~km}$ at its widest. 
Primary producer biomass, benthic consumer biomass, and stable isotope data used in this model were obtained from (Lebreton et al., 2012; 2009). Sampling was conducted at two stations (a high flat station and a low flat station) in 2006 and 2007 (Figure 1) and the results were averaged (Table 1). Each station was a homogeneous area of $100 \mathrm{~m}^{2}$ parallel to the coastline, about $250 \mathrm{~m}$ from the upper and lower limits of the seagrass bed, respectively. The stations were each broken up into 100 plots of $1 \mathrm{~m}^{2}$ for sampling. Both sampling sites were exposed at every low tide, with the higher in elevation of the two sites being exposed for 5 hours longer on average (Lebreton et al., 2009). Average emersion times on the seagrass bed were computed for this study using bathymetric data and tidal measurements, and those processes (i.e., phytoplankton production, bird grazing, zooplankton grazing, etc.) affected by the tidal cycle were scaled accordingly in the food web model.

\subsection{Linear Inverse Model (LIM-MCMC) formulation}

Two inverse food web models were built to track the flow of carbon through the seagrass food web on an annual basis, with units of $\mathrm{mgC} \mathrm{m} \mathrm{m}^{-2} \mathrm{~d}^{-1}$. The first model (Traditional LIM) included all available data, with the exception of the diet constraints formed from the stable isotope mixing models. The second LIM (Isotope LIM) was identical to the Traditional LIM, but included the SIAR diet constraints. Both models were identical in structure, and intended to model the same Marennes-Oleron intertidal seagrass bed.

First, an a priori topological model was formulated of the food web based on local expert knowledge and previous studies (Leguerrier et al., 2003; 2004), defining the 
compartments and all probable connections between them. All macrofaunal species sampled in the system were included which had a biomass of at least $0.05 \mathrm{~g}$ ash-free dry weight $\mathrm{m}^{-2}$. This biomass threshold value resulted in $96.5 \%$ of the total measured biomass during sampling being included in the inverse food web model. The benthic and pelagic fauna of the system were parsed into compartments based on similarity of species-specific characteristics such as taxonomy, habitat, known feeding habits, known predators, and stable isotope $\left(\delta^{13} \mathrm{C}\right.$ and $\left.\delta^{15} \mathrm{~N}\right)$ values. Priority was placed on aggregating species into the compartments in such a way so as to balance between maintaining the true trophic complexity of the ecosystem versus the need to keep the model simple enough that solutions could be produced in a timely manner. As the complexity of the model scales exponentially with the number of compartments, some aggregation was necessary. However, loss in precision of stable isotope data due to aggregation of species with dissimilar signatures was considered to be undesirable for the mixing models, and was therefore avoided. Previous studies found that a priori model aggregation at low trophic levels has a greater effect on inverse model results than does aggregation of higher trophic levels (Johnson et al., 2009). In light of these results, primary producers, bacteria, and non-living carbon pools (e.g., dissolved organic carbon) were each given their own compartment. The resulting a priori food web model consisted of 26 compartments (23 living, 3 detrital) (Table 1) and 175 flows among compartments (Table 2).

The Traditional LIM and Isotope LIM were run using a Matlab routine that was a translation of the R packages limSolve and xsample (Kones et al., 2009; Van den Meersche et al., 2009; van Oevelen et al., 2010). The routine uses a Markov Chain 
Monte Carlo (MCMC) algorithm to sample the LIM solution space using random jumps of a user-defined length. A "mirror" algorithm within the Matlab program creates a set of hyperplanes that form a convex solution space based on the equality and inequality constraints, out of which the sampling procedure cannot exit (Van den Meersche et al., 2009). These hyperplanes act as mirrors, which the random jumps are reflected by, and that ensure the samples are always taken from within the LIM feasible solution space. This procedure reduces the number of iterations required to fully characterize the solution space when compared with a solution procedure whose searching is not constrained to within the feasible solution space, as all samples of the mirror algorithm procedure are feasible solutions. Adequate sampling of the solution space and convergence was ensured through visual inspection of the sampling and results for each flow of the food web model. Note that the models were solved using the LIM-MCMC technique as described above, but will be referred to as the Traditional LIM and Isotope LIM for simplicity.

\subsection{Stable isotope mixing models}

The analytical precision of the stable isotope measurements was $<0.15 \%$ and $<0.2 \%$ for $\delta 13 \mathrm{C}$ and $\delta 15 \mathrm{~N}$ values, respectively (Lebreton et al., 2012). Trophic enrichment factors used were $0.5 \%+/-0.5$ for $\delta 13 \mathrm{C}$ and $2.5 \%+/-1.0$ for $\delta 15 \mathrm{~N}$ (Vander Zanden and Rasmussen, 2001)(Vander Zanden and Rasmussen, 2001).

The SIAR isotopic mixing model (Parnell et al., 2010) was used to characterize the proportions of food sources used by the consumers in the seagrass bed. SIAR is an open-source $\mathrm{R}$ package that uses Bayesian inference to address natural variation and 
uncertainty of stable isotope data in order to generate probability distributions of food source contributions as percentages of the total diet. SIAR allows for multiple dietary sources, incorporates variability in source, consumer and trophic enrichment factors. As a result, output probability estimates reflect uncertainties in the data better than previous mixing models (Parnell et al., 2010; Phillips and Gregg, 2003; 2001; Phillips et al., 2005). A critical assumption of isotope mixing models is that all food sources are included in the analysis. Excluding a food source will bias the apparent proportions of the other sources that were included in the analysis, and may yield a diet with apparent food source proportions inconsistent with the observed isotopic composition of the consumer (Parnell et al., 2012; Phillips, 2012). In order to meet this assumption, SIAR mixing models were only run for those LIM compartments whose food sources all had both $\delta^{13} \mathrm{C}$ and $\delta^{15} \mathrm{~N}$ values. Models were not run for those LIM compartments whose food sources were not all described by both $\delta^{13} \mathrm{C}$ and $\delta^{15} \mathrm{~N}$ data. For example, because the fish in the seagrass bed are known to be transitory, it cannot be assumed that all of their food sources are described by isotope data only collected from the within the seagrass bed. SIAR mixing models were therefore not run for this compartment. Of the 20 heterotrophic compartments in the LIM for which mixing models could potentially be used, 12 compartments met the assumptions required for a SIAR model to be run (Table 2). The $5 \%$ and $95 \%$ credible bounds of the generated probability density functions (PDF), expressed as percent contribution to the mixture for each food source, were recorded and used as input to the inverse model, as explained below. Credible intervals are used in Bayesian statistics to define the domain of a posteriori probability distribution used for interval estimation (e.g., if the $0.90 \mathrm{CI}$ of a contribution value ranges from $\mathrm{A}$ to $\mathrm{B}$, it 
means that there is a $90 \%$ chance that the contribution value lies between A and B) (Lebreton et al., 2012).

\subsection{Incorporation of mixing model data into the food web model}

The 5\% and 95\% credible bounds of the PDF for each food source were used as lower and upper bounds, respectively, to constrain the relative contributions of each food source to the 12 consumer compartments modeled using SIAR. In order to be incorporated into the food web model, these lower and upper bounds were transformed into linear inequalities of the form:

lower bound: $C_{i, j}-l * \sum C_{., j} \geq 0$

upper bound: $h * \sum C_{., j}-C_{i, j} \geq 0$

where, $C_{i, j}$ is the flow of carbon from source $\mathrm{i}$ to consumer $\mathrm{j}, \sum C_{., j}$ is the sum of all source flows to consumer $\mathrm{j}, l$ is the $5 \%$ credible bound for $\%$ mixture contribution, and $h$ is the $95 \%$ credible bound for $\%$ mixture contribution. Using this methodology, if consumer $\mathrm{j}$ had three potential food sources, six inequalities were entered into the food web model to describe consumer j's diet. Note that while the food web model used carbon as the currency for mass flow, and these isotopic inequalities were written following this form, the values were informed by both $\delta^{13} \mathrm{C}$ and $\delta^{15} \mathrm{~N}$ data via the SIAR modeling process.

\subsection{Investigating effects of isotopic constraints on the food web model}


Two versions of the food web model were created to investigate the effects of using isotopic constraints on the estimated mass flows among compartments within the

food web. A first model (Traditional LIM) was built using all available data except the isotopic constraints. The second model (Isotope LIM) was identical to the first model, but included the SIAR-derived isotopic constraints. Each model was run for 50,000 solutions using the LIM-MCMC technique, and convergence to the marginal probability density function (mPDF) for individual flows was verified for both models. Nonconvergence manifests itself as a drift in the mPDF with increased iterations (Kones et al., 2009).

Network indices were calculated for both food web models following the techniques of ecological network analysis (ENA) (Baird et al., 2009; Christian et al., 2009; Ulanowicz, 2004). These indices describe ecosystem network properties, interactions, and emergent properties of the system that are not otherwise directly observable (Fath et al., 2007). Indices computed were total system throughput, average path length, internal ascendency, internal development capacity, ascendency, development capacity, Finn cycling index and the comprehensive cycling index (Baird et al., 2004; Ulanowicz, 2004).

\section{RESULTS}

\subsection{SIAR mixing models}

SIAR mixing models for the 12 consumer compartments whose food sources were fully described with $\delta^{13} \mathrm{C}$ and $\delta^{15} \mathrm{~N}$ data resulted in probability distributions of food source proportions for each compartment. The 5\% and $95 \%$ credible bounds for each 
potential food source were used as lower and upper bounds of relative contribution to the consumer diet. These resulting 90\% credible intervals used in the LIM-MCMC are shown in Table 2.

\subsection{Effects of isotopic constraints on the food web model}

Sixty-four of the 175 flows in the Isotope LIM were constrained using SIARderived dietary constraints. The mean value for each flow and the corresponding $90 \%$ interquantile range (95\% credible interval value $-5 \%$ credible interval value) are presented in Table 3. Seventy-nine (45\%) and 43 (24\%) of the means for the 175 flows were different between the Isotope and the Traditional LIMs by at least $10 \%$ and 25\%, respectively (Table 3). Of the 64 flows which were constrained with SIAR-derived dietary constraints, 50 had their means change by at least $10 \%$, and 31 had their means change by at least $25 \%$. On average, all flows had a $23 \%$ absolute mean difference for the Isotope LIM in comparison with the Traditional; similarly the $90 \%$ interquantile ranges of the flows were reduced by $26 \%$ for the Isotope LIM in comparison with the Traditional LIM (Table 4). Flows constrained in the Isotope LIM using SIAR-derived diet constraints had, on average, a $42 \%$ absolute mean difference in comparison with the corresponding Traditional LIM flows, and their $90 \%$ interquantile ranges were reduced 45\%. Additionally, the remaining 111 flows (those that were not directly constrained with SIAR-derived diet constraints in the Isotope LIM) had, on average, a $12 \%$ absolute mean difference, and $90 \%$ interquantile ranges were reduced by $15 \%$ on average.

All network indices (total system throughput, average path length, internal ascendency, internal development capacity, ascendency, development capacity, Finn 
cycling index and comprehensive cycling index) calculated from the Traditional and Isotope LIMs had small differences in their means (Table 5). Changes in the $90 \%$ interquantile ranges with the addition of the SIAR-derived isotope constraints in the Isotope LIM were small when compared with the Traditional LIM (Table 5).

\section{DISCUSSION}

\subsection{Comparison of single flows and integrative indices between LIMs}

Both individual flows and integrative indices as calculated from ENA parameters were changed as a result of the addition of the SIAR-derived dietary constraints in the Isotope LIM. However, the comparison of the ENA indices showed smaller differences in the means, uncertainty ( $90 \%$ interquantile ranges), and marginal probability distributions between the Traditional and Isotope LIMs when compared to those differences between individual flows. This agrees with the findings of Kones et al. (2009), who found that whole network indices are better constrained and more robust than the food webs from which they are calculated. Differences between the two models were more apparent when looking at the individual flow level as compared to a more aggregate, whole system measure (i.e., ENA indices). This suggests that the integration of the stable isotope data has the largest effect when looking at specific flows within the food web. Linear inverse models are most often utilized to quantify systems with a large number of unknown flows and data deficiencies. The fact that the integrative indices calculated from the Traditional and Isotope LIMs show small differences suggests that the LIM-MCMC technique is a robust method for assessing whole-ecosystem properties, even in the absence of site-specific stable isotope data. 
Generally, the largest differences seen between the Traditional and Isotope LIMs were in those flows which were directly constrained by SIAR-derived diet constraints (Table 4). However, flows not directly constrained with isotope data were still affected, as evidenced by the reduced uncertainty and changes in means. This demonstrates the interconnected nature of the food web, as well as how constraining some flows with isotope data can have widespread effects on reducing uncertainty in LIM-MCMC models.

\subsection{Integration of stable isotope data in food web models}

The goal of this study was to find a way to incorporate information from multiple stable isotope elements (i.e., ${ }^{13} \mathrm{C},{ }^{15} \mathrm{~N}$, etc.) into food web models using the LIM-MCMC technique, with minimum added complexity. The technique of using SIAR-derived food source contribution constraints successfully integrated $\delta^{13} \mathrm{C}$ and $\delta^{15} \mathrm{~N}$ information into the LIM-MCMC models. Analysis of LIM-MCMC output showed the Isotope LIM to be significantly different, as well as significantly more precise, than the Traditional LIM. Thus, the integration of $\delta^{13} \mathrm{C}$ and $\delta^{15} \mathrm{~N}$ data into the food web model through isotope mixing model diet constraints succeeded in reducing the uncertainty of the food web model solution. Van Oevelen et al. (2006) found, similarly, that inclusion of $\delta^{13} \mathrm{C}$ data significantly constrained a conventional LIM of a benthic intertidal flat food web. This study builds on this finding by simultaneously including stable isotope information from two markers $\left(\delta^{13} \mathrm{C}\right.$ and $\left.\delta^{15} \mathrm{~N}\right)$, as well as using stochastic techniques to fully describe the food web model solution space and associated uncertainty.

The use of the SIAR mixing models allowed for incorporation of uncertainty in both the measured stable isotope values, as well as the fractionation factors. 
Incorporating the $90 \%$ credible intervals from the mixing models into the LIM-MCMC in the form of inequalities agrees well with conventional practices for building linear inverse models and is relatively simple to do, but comes at the cost of losing information regarding the tails of the marginal posterior distributions. Future models may choose to incorporate this information in a similar fashion to Hosack and Eldridge (2009), though this would add significant complexity. This methodology allows for data from multiple isotopic markers to be used in order to estimate contributions from all likely food sources to each consumer. It is well established that a multiple marker approach $\left(\delta^{13} \mathrm{C}\right.$ and $\left.\delta^{15} \mathrm{~N}\right)$ is significantly more informative when estimating diet contributions when compared to a single marker $\left(\delta^{13} \mathrm{C}\right.$ or $\left.\delta^{15} \mathrm{~N}\right)$ (Parnell et al., 2012; Phillips, 2012). Due to this, use of stable isotope mixing models in ecosystem-level food web studies can be advantageous for quantifying consumption flows. These same food web flows are often the most difficult to directly observe and measure as well, making isotopic mixing models a powerful tool for coupling with ecosystem-level food web models. This study used only two isotopic markers $\left(\delta^{13} \mathrm{C}\right.$ and $\left.\delta^{15} \mathrm{~N}\right)$, as this was the only data available at the time, although the SIAR mixing models allow for incorporation of more than two (Parnell et al., 2010). However, use of isotopic mixing models utilizing more than three markers becomes problematic, as it is difficult to determine the model fit and visualize the mixing space (this would require > three dimensions) (Parnell et al., 2012).

Additionally, the use of the stable isotope mixing models helped validate the $a$ priori food web model by verifying that the consumer diet networks were possible, and not missing a potential food source as indicated by the isotope data. While no statistical test exists for missing food sources (Parnell et al., 2012), visualization of the iso-space 
for food web compartments is a tool that ecologists can use to identify probable predatorprey relationships. As mentioned, multiple isotopic markers help to better elucidate these relationships. Perhaps most importantly, though, is the fact that the stable isotope data specifically constrain consumption flows, which are often the most difficult to obtain reliable data on. This difficulty in obtaining reliable data leads to many ecosystem network models using diet data not specific to the study site of interest, such as from databases like FishBase (www.fishbase.org) (Coll et al., 2011). This can be a dangerous practice, as it has been shown that there can be considerable inter-site variability in the diet of members of the same species. We recommend the use of local diet information in the construction of food web models, as can be provided by mixing models utilizing sitespecific stable isotope markers. It is important to note that stable isotope data obtained from the literature or other sites is not useful when building a food web model, as values are site-specific and only comparable within the site and appropriate temporal period from which the stable isotope samples were gathered.

\subsection{Effects of SIAR-derived food source constraints on the modeled food web}

Integration of mixing model constraints into LIM-MCMC models address an obvious weakness of stable isotope mixing models: current commonly used mixing models do not take into account the availability of food sources (Parnell et al., 2010; Phillips and Gregg, 2003; Semmens et al., 2009). Mixture partitioning is dictated purely by the stable isotope signatures of the consumer and food sources, regardless of whether or not there are enough of those food sources in the system to support the level of consumption suggested by the mixing model. The LIM-MCMC model deals with this 
issue through mass balance of each compartment, and incorporating field-measured biomass estimates for each compartment into the model. This constrains the biomass of each compartment in the model, and therefore the amount available for consumption. While a simple concept, this is nonetheless an important attribute of ecosystem models, and an example of how the combination of isotope mixing models with inverse food web models is quite beneficial.

The use of the Markov-Chain Monte Carlo method (van Oevelen et al., 2010) to solve the models enabled the statistical comparison to be done between the Traditional and Isotope models. Previous techniques, which relied on minimization of an objective function to choose one answer for a model, did not allow for statistically rigorous comparisons between models (Vezina and Platt, 1988). Comparison of the mPDFs of each flow allowed for utilization of all solution data from the models, as well as taking into account the uncertainty associated with each flow. The same concept applied to the comparisons of the ENA indices. The LIM-MCMC technique also allows for the repeatability of model solutions, which is imperative for future comparative ecosystem studies.

\section{Acknowledgments:}

The present study was carried out at the University of La Rochelle, France and Oregon State University, United States, and partially funded by the European research programs PNEC, EC2CO, COMPECO, ORIQUART, and the Région Poitou Charentes. We are grateful to all of our colleagues who made data available and helped with the modeling process, including Boutheina Grami, Blanche Saint-Béat, and Geoffrey R. 
Hosack. This document has been subjected to review by the National Health and Environmental Effects Research Laboratory's Western Ecology Division and approved for publication. Approval does not signify that the contents reflects the views of the Agency, nor does mention of trade names or commercial products constitute endorsement or recommendation for use. 
Baeta, A., Niquil, N., Marques, J.C., Patrício, J., 2011. Modelling the effects of eutrophication, mitigation measures and an extreme flood event on estuarine benthic food webs. Ecological Modelling 222, 1209-1221.

Baird, D., Asmus, H., Asmus, R., 2004. Energy flow of a boreal intertidal ecosystem, the Sylt-Rømø Bight. Mar. Ecol. Prog. Ser 279, 45-61.

Baird, D., Fath, B., Ulanowicz, R., Asmus, H., 2009. On the consequences of aggregation and balancing of networks on system properties derived from ecological network analysis. Ecological Modelling 279, 45-61.

Banašek-Richter, C., Cattin, M.-F., Bersier, L.-F., 2004. Sampling effects and the robustness of quantitative and qualitative food-web descriptors. Journal of Theoretical Biology 226, 23-32.

Breed, G., Jackson, G., Richardson, T., 2004. Sedimentation, carbon export and food web structure in the Mississippi River plume described by inverse analysis. Mar. Ecol. Prog. Ser 278, 35-51.

Christensen, V., Pauly, D., 1992. Ecopath II—a software for balancing steady-state ecosystem models and calculating network characteristics. Ecological Modelling 61, 169-185.

Christian, R., Brinson, M., Dame, J., Johnson, G., 2009. Ecological network analyses and their use for establishing reference domain in functional assessment of an estuary. Ecological Modelling 220, 3113-3122.

Coll, M., Schmidt, A., Romanuk, T., Lotze, H.K., 2011. Food-Web Structure of Seagrass Communities across Different Spatial Scales and Human Impacts. PLoS One 6, e22591. 
Daniels, R., Richardson, T., Ducklow, H., 2006. Food web structure and biogeochemical processes during oceanic phytoplankton blooms: an inverse model analysis. Deep Sea Research Part II: Topical Studies in Oceanography 53, 532-554.

Degré, D., Leguerrier, D., Armynot du Chatelet, E., Rzeznik, J., Auguet, J., Dupuy, C., Marquis, E., Fichet, D., Struski, C., Joyeux, E., 2006. Comparative analysis of the food webs of two intertidal mudflats during two seasons using inverse modelling: Aiguillon Cove and Brouage Mudflat, France. Estuarine, Coastal and Shelf Science 69, 107-124.

Donali, E., Olli, K., Heiskanen, A., Andersen, T., 1999. Carbon flow patterns in the planktonic food web of the Gulf of Riga, the Baltic Sea: a reconstruction by the inverse method. Journal of Marine Systems 23, 251-268.

Eldridge, P., Cifuentes, L., Kaldy, J., 2005. Development of a stable-isotope constraint system for estuarine food-web models. Mar. Ecol. Prog. Ser 303, 73-90.

Eldridge, P., Jackson, G., 1993. Benthic trophic dynamics in California coastal basin and continental slope communities inferred using inverse analysis. Mar. Ecol. Prog. Ser $99,115-115$.

Fath, B.D., Scharler, U.M., Ulanowicz, R.E., Hannon, B., 2007. Ecological network analysis: network construction. Ecological Modelling 208, 49-55.

Grami, B., Niquil, N., Sakka Hlaili, A., Gosselin, M., Hamel, D., Hadj Mabrouk, H., 2008. The plankton food web of the Bizerte Lagoon (South-western Mediterranean): II. Carbon steady-state modelling using inverse analysis. Estuarine, Coastal and Shelf Science 79, 101-113.

Grami, B., Rasconi, S., Niquil, N., Jobard, M., Saint-Béat, B., Sime-Ngando, T., 2011. 
Functional Effects of Parasites on Food Web Properties during the Spring Diatom Bloom in Lake Pavin: A Linear Inverse Modeling Analysis. PLoS One 6, e23273. Hosack, GR and PM Eldridge. 2009. Do microbial processes regulate the stability of a coral atoll's enclosed pelagic ecosystem? Ecological Modelling 220, 2665-2682.

Jackson, G., Eldridge, P., 1992. Food web analysis of a planktonic system off Southern California. Progress in Oceanography 30, 223-251.

Johnson, G., Niquil, N., Asmus, H., Bacher, C., 2009. The effects of aggregation on the performance of the inverse method and indicators of network analysis. Ecological Modelling 220, 3448-3464.

Kones, J., Soetaert, K., van Oevelen, D., Owino, J., 2009. Are network indices robust indicators of food web functioning? a monte carlo approach. Ecological Modelling $220,370-382$.

Kones, J., Soetaert, K., van Oevelen, D., Owino, J., Mavuti, K., 2006. Gaining insight into food webs reconstructed by the inverse method. Journal of Marine Systems 60, $153-166$.

Lebreton, B., Richard, P., Galois, R., Radenac, G., Brahmia, A., Colli, G., Grouazel, M., André, C., Guillou, G., Blanchard, G.F., 2012. Food sources used by sediment meiofauna in an intertidal Zostera noltii seagrass bed: a seasonal stable isotope study. Marine Biology 159, 1537-1550.

Lebreton, B., Richard, P., Radenac, G., Bordes, M., Breret, M., Arnaud, C., Mornet, F., Blanchard, G., 2009. Are epiphytes a significant component of intertidal Zostera noltii beds? Aquatic Botany 91, 82-90.

Leguerrier, D., Degré, D., Niquil, N., 2007. Network analysis and inter-ecosystem 
comparison of two intertidal mudflat food webs (Brouage Mudflat and Aiguillon

Cove, SW France). Estuarine, Coastal and Shelf Science 74, 403-418.

Leguerrier, D., Niquil, N., Boileau, N., Rzeznik, J., Sauriau, P., Le Moine, O., Bacher, C., 2003. Numerical analysis of the food web of an intertidal mudflat ecosystem on the Atlantic coast of France. Mar. Ecol. Prog. Ser 246, 17-37.

Leguerrier, D., Niquil, N., Petiau, A., Bodoy, A., 2004. Modeling the impact of oyster culture on a mudflat food web in Marennes-Oléron Bay (France). Mar. Ecol. Prog. Ser. $273,147-161$.

Leslie, H.M., McLeod, K.L., 2007. Confronting the challenges of implementing marine ecosystem-based management. Frontiers in Ecology and the Environment 5, 540548.

Moore, J., Semmens, B., 2008. Incorporating uncertainty and prior information into stable isotope mixing models. Ecology Letters 11, 470-480.

Navarro, J., Coll, M., Louzao, M., Palomera, I., Delgado, A., Forero, M., 2011. Comparison of ecosystem modelling and isotopic approach as ecological tools to investigate food webs in the NW Mediterranean Sea. Journal of Experimental Marine Biology and Ecology 401, 97-104.

Niquil, N., Bartoli, G., Urabe, J., Jackson, G., Legendre, L., Dupuy, C., Kumagai, M., 2006. Carbon steady-state model of the planktonic food web of Lake Biwa, Japan. Freshwater Biology 51, 1570-1585.

Niquil, N., Chaumillon, E., Johnson, G.A., Bertin, X., Grami, B., David, V., Bacher, C., Asmus, H., Baird, D., Asmus, R., 2012. The effect of physical drivers on ecosystem indices derived from ecological network analysis: Comparison across estuarine 
ecosystems. Estuarine, Coastal and Shelf Science 108, 132-143.

Niquil, N., Jackson, G., Legendre, L., Delesalle, B., 1998. Inverse model analysis of the planktonic food web of Takapoto Atoll (French Polynesia). MEPS 165, 17-29.

Oevelen, D., Meersche, K., Meysman, F.J.R., Soetaert, K., Middelburg, J.J., Vézina, A.F., 2010. Quantifying Food Web Flows Using Linear Inverse Models. Ecosystems $13,32-45$.

Parnell, A., Inger, R., Bearhop, S., Jackson, A., 2010. Source partitioning using stable isotopes: coping with too much variation. PLoS One 5, e9672.

Parnell, A.C., Phillips, D.L., Bearhop, S., 2012. Bayesian Stable Isotope Mixing Models. arXiv:1209.6457v1.

Pauly, D., 2000. Ecopath, Ecosim, and Ecospace as tools for evaluating ecosystem impact of fisheries. ICES Journal of Marine Science 57, 697-706.

Phillips, D., Gregg, J., 2001. Uncertainty in source partitioning using stable isotopes. Oecologia 127, 171-179.

Phillips, D., Gregg, J., 2003. Source partitioning using stable isotopes: coping with too many sources. Oecologia 136, 261-269.

Phillips, D., Newsome, S., Gregg, J., 2005. Combining sources in stable isotope mixing models: alternative methods. Oecologia 144, 520-527.

Phillips, D.L., 2012. Converting isotope values to diet composition: the use of mixing models. Journal of Mammalogy 93, 342-352.

Post, D., 2002. Using stable isotopes to estimate trophic position: models, methods, and assumptions. Ecology 83, 703-718.

Semmens, B.X., Moore, J.W., Ward, E.J., 2009. Improving Bayesian isotope mixing 
models: a response to Jacksonet al.(2009). Ecology Letters 12, E6-E8.

Ulanowicz, R., 2004. Quantitative methods for ecological network analysis.

Computational Biology and Chemistry 28, 321-339.

Van den Meersche, K., Soetaert, K., van Oevelen, D., 2009. xsample (): An R Function for Sampling Linear Inverse Problems. Journal of Statistical Software, Code Snippets $30,1-15$.

van Oevelen, D., Soetaert, K., Middelburg, J., Herman, P., Moodley, L., Hamels, I., Moens, T., Heip, C., 2006. Carbon flows through a benthic food web: Integrating biomass, isotope and tracer data. Journal of Marine Research 64, 453-482.

van Oevelen, D., Van den Meersche, K., Meysman, F., Soetaert, K., Middelburg, J., Vézina, A., 2010. Quantifying Food Web Flows Using Linear Inverse Models. Ecosystems 13, 32-45.

Vander Zanden, M.J., Rasmussen, J.B., 2001. Variation in $\delta 15 \mathrm{~N}$ and $\delta 13 \mathrm{C}$ trophic fractionation: implications for aquatic food web studies. Limnology and Oceanography 46, 2061-2066.

Vezina, A., Platt, T., 1988. Food web dynamics in the ocean. 1. Best-estimates of flow networks using inverse methods. Marine Ecology Progress Series. Oldendorf 42, 269-287.

Walters, C., Christensen, V., Pauly, D., 1997. Structuring dynamic models of exploited ecosystems from trophic mass-balance assessments. Reviews in fish biology and fisheries 7, 139-172. 
Table 1. Food web compartments, along with their biomasses and stable isotope values used in the Traditional and Isotope LIMs.

\begin{tabular}{|c|c|c|c|c|c|c|}
\hline Compartment & $\begin{array}{c}\text { Compartment } \\
\text { abbreviation }\end{array}$ & Biomass (mgC m ${ }^{-2}$ ) & $\begin{array}{c}\delta^{13} \mathrm{C} \\
\text { mean } \\
\end{array}$ & $\begin{array}{l}\delta^{13} \mathrm{C} \\
\mathrm{SD} \\
\end{array}$ & $\begin{array}{c}\delta^{15} \mathrm{~N} \\
\text { mean } \\
\end{array}$ & $\begin{array}{l}\delta^{15} \mathbf{N} \\
\text { SD } \\
\end{array}$ \\
\hline \multicolumn{7}{|l|}{ AUTOTROPHS } \\
\hline Microphytobenthos & $\mathrm{mpb}$ & 9,250 & -14.00 & 1.07 & 5.68 & 1.29 \\
\hline Zostera noltii & zos & 6,133 & -10.98 & 1.06 & 8.46 & 1.53 \\
\hline Phytoplankton & phy & 254.5 & -23.70 & 2.37 & 4.90 & 0.49 \\
\hline \multicolumn{7}{|l|}{ DETRITUS } \\
\hline $\begin{array}{l}\text { Dissolved Organic } \\
\text { Carbon }\end{array}$ & doc & 1,850 & - & - & - & - \\
\hline Sediment Organic Matter & som & 27,560 & -19.00 & 0.92 & 5.80 & 1.08 \\
\hline $\begin{array}{l}\text { Particulate Organic } \\
\text { Matter }\end{array}$ & pom & 1,044 & -21.09 & 2.84 & 5.80 & 1.08 \\
\hline \multicolumn{7}{|l|}{ HETEROTROPHS } \\
\hline Benthic Bacteria & bba & 4,718 & - & - & - & - \\
\hline Pelagic Bacteria & pba & 157.3 & - & - & - & - \\
\hline Zooplankton & zoo & 160.0 & -24.35 & 2.43 & 7.39 & 0.74 \\
\hline Hydrobia ulvae & hyd & 3,752 & -12.02 & 1.03 & 9.73 & 0.64 \\
\hline Nematodes & nem & 2,748 & -12.83 & 0.61 & 9.80 & 0.73 \\
\hline Tapes spp & tap & 844.1 & -16.94 & 1.79 & 9.15 & 0.79 \\
\hline Cerastoderma edule & cer & 352.5 & -16.99 & 1.19 & 9.83 & 0.97 \\
\hline Copepods & cop & 359.0 & -15.45 & 1.10 & 7.80 & 0.42 \\
\hline Gastropod grazers & gas & 325.0 & -11.50 & 1.11 & 10.18 & 1.29 \\
\hline Scrobicularia plana & scr & 258.3 & -14.28 & 0.71 & 9.98 & 1.06 \\
\hline Mytilus galoprovincialis & myt & 127.1 & -18.14 & 1.86 & 9.47 & 0.75 \\
\hline Abra spp & abr & 69.59 & -13.52 & 1.07 & 11.47 & 1.91 \\
\hline Macoma balthica & mac & 48.31 & -13.38 & 0.53 & 11.07 & 2.23 \\
\hline Cerebratulus marginatus & ceb & 14.22 & -14.67 & 2.24 & 10.00 & 0.42 \\
\hline Carcinus maenas & car & 25.96 & -12.58 & 0.82 & 11.44 & 0.46 \\
\hline Crangon crangon & cra & 10.66 & -12.99 & 1.02 & 12.92 & 0.59 \\
\hline Notomastus latericeus & not & 18.10 & -13.87 & 1.16 & 13.10 & 2.18 \\
\hline Arenicola marina & are & 11.15 & -13.68 & 0.58 & 11.31 & 0.14 \\
\hline Fish & fsh & 195.0 & -15.11 & 3.29 & 13.08 & 2.14 \\
\hline Birds & brd & 7.00 & - & - & - & - \\
\hline
\end{tabular}


Table 2. SIAR-derived dietary contribution matrix. Lower and upper bounds of the $90 \%$ credible intervals are given, with consumers by row and prey items by column. Values are in units of percent contribution to total diet.

\begin{tabular}{|c|c|c|c|c|c|c|c|c|c|c|c|c|c|c|c|c|c|c|c|c|c|c|c|c|c|c|}
\hline $\begin{array}{c}\text { Isotope \% } \\
\text { diet matrix }\end{array}$ & 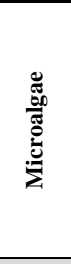 & 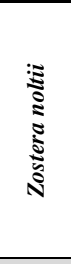 & 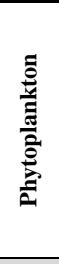 & 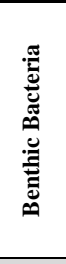 & 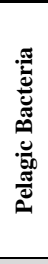 & 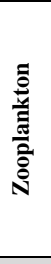 & 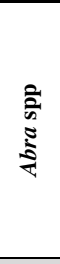 & 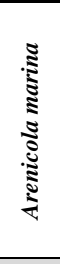 & $\stackrel{0}{=0}$ & 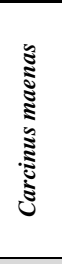 & 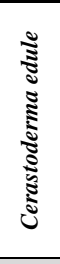 & 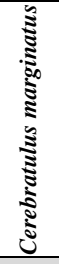 & $\begin{array}{l}\frac{n}{0} \\
\dot{0} \\
\tilde{0}\end{array}$ & 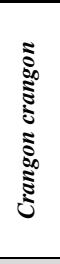 & $\frac{\sqrt[n]{2}}{2}$ & 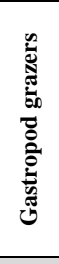 & 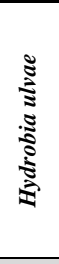 & 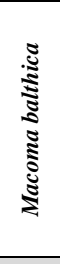 & 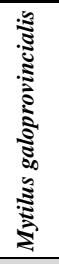 & 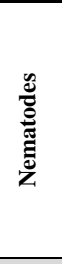 &  & 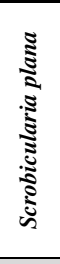 & 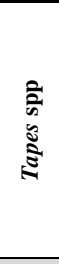 & Ø & $\sum_{0}$ & $\sum_{0}$ \\
\hline Abra spp & $0-60$ & $21-69$ & & & & & & & & & & & & & & & & & & & & & & & & $9-45$ \\
\hline $\begin{array}{l}\text { Carcinus } \\
\text { maenas }\end{array}$ & & & & & & $0-8$ & $0-13$ & $0-13$ & & & $0-10$ & $0-13$ & $0-15$ & $0-13$ & $0-10$ & $0-21$ & $0-20$ & $0-14$ & $0-10$ & $0-18$ & $0-11$ & $0-14$ & $0-11$ & & & $0-15$ \\
\hline $\begin{array}{l}\text { Cerastoderma } \\
\quad \text { edule }\end{array}$ & $28-59$ & & $0-23$ & & & & & & & & & & & & & & & & & & & & & & $0-40$ & $1-54$ \\
\hline $\begin{array}{l}\text { Cerebratulus } \\
\text { marginatus }\end{array}$ & $1-37$ & $0-30$ & & & & & & & & & & & $0-42$ & & & & & & & & $0-35$ & & & & $5-42$ & \\
\hline $\begin{array}{l}\text { Crangon } \\
\text { crangon }\end{array}$ & & & & & & $0-8$ & $0-13$ & $0-13$ & & $0-14$ & $0-12$ & $0-14$ & $0-17$ & & & $0-19$ & $0-18$ & $0-13$ & $0-11$ & $0-17$ & $0-11$ & $0-14$ & $0-12$ & & & $0-14$ \\
\hline $\begin{array}{l}\text { Scrobicularia } \\
\text { plana }\end{array}$ & 79-96 & & $0-11$ & & & & & & & & & & & & & & & & & & & & & & $0-16$ & \\
\hline Tapes spp & $39-65$ & & $0-22$ & & & & & & & & & & & & & & & & & & & & & & $17-60$ & \\
\hline $\begin{array}{c}\text { Mytilus } \\
\text { galoprovincialis }\end{array}$ & $22-52$ & & $10-55$ & & & & & & & & & & & & & & & & & & & & & & $2-55$ & \\
\hline Hydrobia ulvae & $12-53$ & $34-70$ & & $0-24$ & & & & & & & & & & & & & & & & & & & & & & $0-16$ \\
\hline $\begin{array}{l}\text { Gastropod } \\
\text { grazers }\end{array}$ & $21-34$ & $59-83$ & & $0-14$ & & & & & & & & & & & & & & & & & & & & & & $0-11$ \\
\hline $\begin{array}{c}\text { Arenicola } \\
\text { marina }\end{array}$ & $0-41$ & $21-60$ & & $21-56$ & & & & & & & & & & & & & & & & & & & & & & \\
\hline Copepods & $38-98$ & & & $2-62$ & & & & & & & & & & & & & & & & & & & & & & \\
\hline
\end{tabular}


Table 3. Flow means and 90\% interquantile ranges of the Traditional and Isotope LIMs.

Statistics are calculated with $n=50,000$ for each model (the number of Monte-Carlo simulations). $90 \%$ interquantile ranges are calculated as the $95 \%$ quantile value minus the $5 \%$ interquantile value. Units are $\mathrm{mg} \mathrm{C} \mathrm{m}^{-2} \mathrm{~d}^{-1}$. Each flow is composed of the abbreviation of the source compartment (see table 1) TO the abbreviation of the sink compartment. gpp = gross primary production, imp $=$ import, $\exp =$ export and res $=$ respiration.

\begin{tabular}{|c|c|c|c|c|c|}
\hline \multirow{2}{*}{\multicolumn{2}{|c|}{ Flow (sourceTOsink) }} & \multicolumn{2}{|c|}{ Traditional Model } & \multicolumn{2}{|c|}{ Isotopic Model } \\
\hline & & \multirow{2}{*}{$\frac{\text { mean }}{1357}$} & \multirow{2}{*}{$\begin{array}{l}90 \% \text { interquantile } \\
\text { range }\end{array}$} & \multirow{2}{*}{$\frac{\text { mean }}{1355}$} & \multirow{2}{*}{$\begin{array}{l}90 \% \text { interquantile } \\
\text { range }\end{array}$} \\
\hline 1 & gрpTOmpb & & & & \\
\hline 2 & gppTOzos & 55.0 & 19.9 & 55.3 & 13.4 \\
\hline 3 & gppTOphy & 58.4 & 43.9 & 57.6 & 45.5 \\
\hline 4 & impTOpba & 88.5 & 16.0 & 88.4 & 15.9 \\
\hline 5 & impTOphy & 150 & 21.4 & 150 & 21.6 \\
\hline 6 & impTOzoo & 94.0 & 13.6 & 94.0 & 13.7 \\
\hline 7 & impTOfsh & 160 & 96.6 & 159 & 96.4 \\
\hline 8 & impTObrd & 4.6 & 2.7 & 4.7 & 2.5 \\
\hline 9 & impTOpom & 598 & 106 & 598 & 106 \\
\hline 10 & impTOdoc & 1067 & 185 & 1064 & 186 \\
\hline 11 & mpbTOres & 323 & 229 & 324 & 228 \\
\hline 12 & mpbTOdoc & 695 & 214 & 695 & 214 \\
\hline 13 & mpbTObba & 142 & 235 & 146 & 208 \\
\hline 14 & mpbTOabr* & 0.8 & 1.9 & 1.0 & 0.8 \\
\hline 15 & mpbTOare** & 0.2 & 0.4 & 0.1 & 0.2 \\
\hline 16 & mpbTObrd** & 7.9 & 19.5 & 0.2 & 0.4 \\
\hline 17 & mpbTOcer** & 2.6 & 6.4 & 4.5 & 3.3 \\
\hline 18 & mpbTOceb & 0.0 & 0.1 & 0.0 & 0.1 \\
\hline 19 & mpbTOcop** & 21.7 & 43.2 & 30.8 & 28.0 \\
\hline 20 & mpbTOfsh & 40.0 & 7.2 & 40.0 & 7.2 \\
\hline 21 & mpbTOgas* & 2.0 & 4.8 & 1.5 & 0.9 \\
\hline 22 & mpbTOhyd* & 47.2 & 114 & 52.2 & 26 \\
\hline 23 & mpbTOmac & 0.2 & 0.6 & 0.2 & 0.6 \\
\hline 24 & mpbTOmyt* & 1.2 & 2.8 & 1.5 & 1.2 \\
\hline 25 & mpbTOnem** & 63.8 & 150 & 41.7 & 101 \\
\hline
\end{tabular}




\begin{tabular}{|c|c|c|c|c|c|}
\hline 26 & mpbTOnot & 0.4 & 0.8 & 0.4 & 0.8 \\
\hline 27 & mpbTOscr** & 2.0 & 4.7 & 5.3 & 1.9 \\
\hline 28 & mpbTOtap** & 6.9 & 15.7 & 10.6 & 6.2 \\
\hline 29 & zosTOres** & 10.9 & 15.2 & 7.5 & 13.4 \\
\hline 30 & zosTOdoc** & 2.0 & 2.4 & 0.9 & 0.3 \\
\hline 31 & zosTOexp** & 5.7 & 15.2 & 0.1 & 0.2 \\
\hline 32 & zosTOsom** & 5.8 & 15.6 & 0.1 & 0.2 \\
\hline 33 & zosTOabr** & 0.8 & 1.8 & 0.6 & 0.3 \\
\hline 34 & zosTOare & 0.2 & 0.4 & 0.2 & 0.1 \\
\hline 35 & zosTObrd** & 22.8 & 23.7 & 0.4 & 0.5 \\
\hline 36 & zosTOceb** & 0.0 & 0.1 & 0.0 & 0.0 \\
\hline 37 & zosTOgas** & 1.6 & 4.1 & 3.5 & 0.5 \\
\hline 38 & zosTOhyd** & 5.4 & 14.7 & 42.2 & 0.5 \\
\hline 39 & phyTOres & 11.3 & 18.2 & 11.2 & 18.2 \\
\hline 40 & phyTOdoc & 6.1 & 4.2 & 6.0 & 4.4 \\
\hline 41 & phyTOexp & 139 & 21.3 & 140 & 21.5 \\
\hline 42 & phyTOpom* & 24.2 & 44.5 & 29.5 & 48.6 \\
\hline 43 & phyTOcer** & 2.6 & 6.3 & 1.2 & 2.2 \\
\hline 44 & phyTOmac & 0.2 & 0.6 & 0.2 & 0.6 \\
\hline 45 & phytOmyt** & 1.2 & 2.8 & 0.8 & 1.4 \\
\hline 46 & phyTOscr** & 2.0 & 4.6 & 0.3 & 0.6 \\
\hline 47 & phyTOtap** & 6.5 & 15.1 & 2.2 & 4.2 \\
\hline 48 & phyTOzoo* & 14.6 & 35.0 & 16.2 & 38.5 \\
\hline 49 & docTOexp & 1036 & 185 & 1038 & 185 \\
\hline 50 & docTOpba & 72.5 & 162 & 72.8 & 162 \\
\hline 51 & docTObba & 937 & 426 & 937 & 423 \\
\hline 52 & pomTOexp & 348 & 456 & 367 & 456 \\
\hline 53 & pomTOsom & 436 & 403 & 433 & 407 \\
\hline 54 & pomTOcer* & 2.6 & 6.5 & 2.0 & 3.7 \\
\hline 55 & pomTOmac & 0.2 & 0.6 & 0.2 & 0.6 \\
\hline 56 & pomTOmyt* & 1.3 & 2.8 & 1.5 & 1.9 \\
\hline 57 & pomTOpba & 87.9 & 176 & 86.2 & 174 \\
\hline 58 & pomTOscr** & 2.1 & 4.6 & 0.5 & 0.9 \\
\hline 59 & pomTOtap & 7.1 & 15.9 & 7.7 & 7.0 \\
\hline 60 & pomTOzoo & 21.6 & 54.1 & 21.1 & 53.5 \\
\hline 61 & somTOexp & 167 & 392 & 172 & 398 \\
\hline 62 & somTOpom & 166 & 399 & 169 & 401 \\
\hline 63 & somTOabr* & 0.8 & 1.9 & 0.7 & 0.7 \\
\hline 64 & somTObba & 237 & 416 & 218 & 397 \\
\hline
\end{tabular}




\begin{tabular}{|c|c|c|c|c|c|}
\hline 65 & somTOcar & 0.1 & 0.2 & 0.1 & 0.1 \\
\hline 66 & somTOceb* & 0.0 & 0.1 & 0.0 & 0.1 \\
\hline 67 & somTOcer & 2.6 & 6.4 & 2.7 & 4.5 \\
\hline 68 & somTOcra & 0.1 & 0.2 & 0.1 & 0.1 \\
\hline 69 & somTOgas** & 2.0 & 4.8 & 0.3 & 0.6 \\
\hline 70 & somTOhyd** & 49.0 & 118 & 10.9 & 18 \\
\hline 71 & somTOmac & 0.2 & 0.6 & 0.2 & 0.6 \\
\hline 72 & somTOnot & 0.4 & 0.8 & 0.4 & 0.8 \\
\hline 73 & bbaTOres & 626 & 234 & 623 & 220 \\
\hline 74 & bbaTOdoc & 103 & 50.9 & 103 & 50.8 \\
\hline 75 & bbaTOare* & 0.2 & 0.4 & 0.2 & 0.2 \\
\hline 76 & bbaTOcop** & 25.3 & 44.0 & 16.2 & 26.6 \\
\hline 77 & \begin{tabular}{|l|} 
bbaTOgas** \\
\end{tabular} & 2.0 & 4.8 & 0.4 & 0.7 \\
\hline 78 & bbaTOhyd** & 72.0 & 135 & 18.5 & 24 \\
\hline 79 & bbaTOnem* & 487 & 170 & 540 & 107 \\
\hline 80 & pbaTOres & 38.7 & 92.4 & 38.7 & 92.5 \\
\hline 81 & pbaTOdoc & 44.0 & 99.9 & 43.4 & 99.2 \\
\hline 82 & pbaTOexp & 90.3 & 16.0 & 90.3 & 16.0 \\
\hline 83 & pbaTOzoo & 75.9 & 62.3 & 75.1 & 62.7 \\
\hline 84 & zooTOres & 51.7 & 16.6 & 51.8 & 16.5 \\
\hline 85 & zooTOdoc & 35.4 & 32.7 & 35.6 & 32.8 \\
\hline 86 & zooTOexp & 88.0 & 13.7 & 88.0 & 13.7 \\
\hline 87 & zooTOpom & 10.4 & 21.4 & 10.4 & 21.4 \\
\hline 88 & zooTOcar** & 0.1 & 0.2 & 0.0 & 0.1 \\
\hline 89 & zooTOcra** & 0.1 & 0.2 & 0.0 & 0.1 \\
\hline 90 & zooTOfsh & 20.5 & 26.7 & 20.5 & 26.7 \\
\hline 91 & abrTOres & 1.3 & 0.2 & 1.3 & 0.2 \\
\hline 92 & abrTOsom* & 0.9 & 0.8 & 0.7 & 0.7 \\
\hline 93 & abrTOcar & 0.1 & 0.2 & 0.1 & 0.1 \\
\hline 94 & abrTOcra & 0.1 & 0.2 & 0.1 & 0.1 \\
\hline 95 & abrTOfsh & 0.1 & 0.2 & 0.1 & 0.2 \\
\hline 96 & areTOres & 0.2 & 0.0 & 0.2 & 0.0 \\
\hline 97 & areTOsom & 0.2 & 0.1 & 0.2 & 0.1 \\
\hline 98 & areTObrd* & 0.0 & 0.0 & 0.0 & 0.0 \\
\hline 99 & areTOcar* & 0.0 & 0.0 & 0.0 & 0.0 \\
\hline 100 & areTOcra* & 0.0 & 0.0 & 0.0 & 0.0 \\
\hline 101 & areTOfsh & 0.0 & 0.0 & 0.0 & 0.0 \\
\hline 102 & brdTOres** & 24.3 & 29.1 & 0.7 & 1.3 \\
\hline 103 & brdTOsom** & 14.6 & 19.2 & 0.4 & 0.6 \\
\hline
\end{tabular}




\begin{tabular}{|c|c|c|c|c|c|}
\hline 104 & brdTOexp & 4.5 & 2.7 & 4.3 & 2.5 \\
\hline 105 & carTOres & 0.4 & 0.1 & 0.4 & 0.1 \\
\hline 106 & carTOsom & 0.4 & 0.2 & 0.4 & 0.2 \\
\hline 107 & carTOcra** & 0.0 & 0.1 & 0.1 & 0.1 \\
\hline 108 & carTofsh* & 0.1 & 0.1 & 0.1 & 0.1 \\
\hline 109 & cerTOres & 5.3 & 0.6 & 5.3 & 0.6 \\
\hline 110 & cerTOsom & 3.8 & 3.2 & 3.8 & 3.2 \\
\hline 111 & cerTOcar** & 0.1 & 0.2 & 0.0 & 0.1 \\
\hline 112 & cerTOcra* & 0.1 & 0.2 & 0.1 & 0.1 \\
\hline 113 & cerTOfsh & 1.1 & 0.4 & 1.1 & 0.3 \\
\hline 114 & cebTOres & 0.1 & 0.0 & 0.1 & 0.0 \\
\hline 115 & cebTOsom & 0.1 & 0.1 & 0.1 & 0.0 \\
\hline 116 & cebTOcar & 0.0 & 0.0 & 0.0 & 0.0 \\
\hline 117 & cebTOcra & 0.0 & 0.0 & 0.0 & 0.0 \\
\hline 118 & cebTOfsh & 0.0 & 0.0 & 0.0 & 0.0 \\
\hline 119 & copTOres & 26.7 & 3.4 & 26.7 & 3.4 \\
\hline 120 & copTOdoc & 12.4 & 17.0 & 12.5 & 17.0 \\
\hline 121 & copTOsom & 7.7 & 16.3 & 7.7 & 16.3 \\
\hline 122 & copTOcar & 0.1 & 0.2 & 0.1 & 0.1 \\
\hline 123 & copTOceb* & 0.0 & 0.1 & 0.0 & 0.1 \\
\hline 124 & copTOcra* & 0.1 & 0.2 & 0.1 & 0.1 \\
\hline 125 & craTOres & 0.4 & 0.1 & 0.4 & 0.1 \\
\hline 126 & craTOsom & 0.4 & 0.2 & 0.4 & 0.2 \\
\hline 127 & craTOcar* & 0.0 & 0.1 & 0.0 & 0.1 \\
\hline 128 & craTOfsh* & 0.0 & 0.1 & 0.0 & 0.1 \\
\hline 129 & fshTOres & 160 & 79.6 & 164 & 74.6 \\
\hline 130 & fshTOpom & 108 & 91.2 & 112 & 92.9 \\
\hline 131 & fshTOexp & 172 & 95.4 & 174 & 95.3 \\
\hline 132 & fshTOcar** & 0.1 & 0.2 & 0.0 & 0.1 \\
\hline 133 & gasTOres* & 3.5 & 0.9 & 3.0 & 0.3 \\
\hline 134 & gasTOsom** & 2.5 & 2.1 & 1.3 & 0.4 \\
\hline 135 & gasTOcar** & 0.1 & 0.2 & 0.1 & 0.2 \\
\hline 136 & gasTOcra** & 0.1 & 0.2 & 0.1 & 0.2 \\
\hline 137 & gasTOfsh* & 1.4 & 0.5 & 1.2 & 0.4 \\
\hline 138 & hydTOres* & 83.0 & 18.1 & 71.9 & 0.6 \\
\hline 139 & hydTOsom** & 59.9 & 49.8 & 26.2 & 0.7 \\
\hline 140 & hydTObrd** & 8.1 & 19.8 & 0.1 & 0.3 \\
\hline 141 & hydTOcar** & 0.1 & 0.2 & 0.1 & 0.2 \\
\hline 142 & hydTOcra* & 0.1 & 0.2 & 0.1 & 0.1 \\
\hline
\end{tabular}




\begin{tabular}{|c|c|c|c|c|c|}
\hline 143 & hydTOfsh* & 22.3 & 22.6 & 25.4 & 0.7 \\
\hline 144 & macTOres & 0.5 & 0.0 & 0.5 & 0.0 \\
\hline 145 & macTOsom & 0.3 & 0.3 & 0.3 & 0.3 \\
\hline 146 & macTOcar* & 0.0 & 0.1 & 0.0 & 0.1 \\
\hline 147 & macTOcra* & 0.0 & 0.1 & 0.0 & 0.1 \\
\hline 148 & macTOfsh* & 0.0 & 0.1 & 0.0 & 0.1 \\
\hline 149 & mytTOres & 1.9 & 0.2 & 1.9 & 0.2 \\
\hline 150 & mytTOsom & 1.4 & 1.2 & 1.4 & 1.2 \\
\hline 151 & mytTOcar** & 0.1 & 0.2 & 0.0 & 0.1 \\
\hline 152 & mytTOcra** & 0.1 & 0.2 & 0.0 & 0.1 \\
\hline 153 & mytTOfsh* & 0.3 & 0.3 & 0.3 & 0.2 \\
\hline 154 & nemTOres & 198 & 71.4 & 207 & 49.7 \\
\hline 155 & nemTOdoc & 80.8 & 158 & 87.4 & 166 \\
\hline 156 & nemTOsom & 80.8 & 158 & 88.5 & 167 \\
\hline 157 & nemTOcar** & 0.1 & 0.2 & 0.1 & 0.2 \\
\hline 158 & nemTOceb & 0.0 & 0.1 & 0.0 & 0.1 \\
\hline 159 & nemTOcra* & 0.1 & 0.2 & 0.1 & 0.1 \\
\hline 160 & nemTOfsh & 192 & 87.9 & 199 & 85.8 \\
\hline 161 & notTOres & 0.4 & 0.1 & 0.4 & 0.1 \\
\hline 162 & notTOsom & 0.3 & 0.3 & 0.3 & 0.3 \\
\hline 163 & notTOcar* & 0.0 & 0.1 & 0.0 & 0.1 \\
\hline 164 & notTOcra* & 0.0 & 0.1 & 0.0 & 0.1 \\
\hline 165 & notTOfsh* & 0.1 & 0.1 & 0.0 & 0.1 \\
\hline 166 & scrTOres & 3.2 & 0.2 & 3.2 & 0.2 \\
\hline 167 & scrTOsom & 2.2 & 1.9 & 2.2 & 1.9 \\
\hline 168 & scrTOcar & 0.1 & 0.2 & 0.1 & 0.1 \\
\hline 169 & scrTOcra & 0.1 & 0.2 & 0.1 & 0.1 \\
\hline 170 & scrTOfsh & 0.6 & 0.3 & 0.6 & 0.2 \\
\hline 171 & tapTOres & 10.8 & 0.7 & 10.8 & 0.7 \\
\hline 172 & tapTOsom & 7.6 & 6.4 & 7.6 & 6.4 \\
\hline 173 & tapTOcar** & 0.1 & 0.2 & 0.0 & 0.1 \\
\hline 174 & tapTOcra* & 0.1 & 0.2 & 0.1 & 0.1 \\
\hline 175 & tapTOfsh & 2.1 & 0.6 & 2.1 & 0.5 \\
\hline
\end{tabular}

Bold: flow with corresponding SIAR diet constraint

* means of Isotope and Traditional LIM $>10 \%$ different

** means of Isotope and Traditional LIM >25\% different 
Table 4. Comparison of means and $90 \%$ interquantile ranges for the Traditional and Isotope LIMs. The absolute mean difference for each flow was calculated as the absolute value of the difference between Traditional and Isotope LIM mean flow values. Negative values indicate a reduction in the interquantile range of the Isotope LIM when compared with the Traditional LIM.

\begin{tabular}{|c|c|c|c|c|c|}
\hline \multicolumn{5}{|c|}{ Average change in statistic after incorporation of isotope information } \\
\hline \multicolumn{2}{|c|}{ All food web flows } & \multicolumn{2}{|c|}{ Flows with SIAR constraints } & \multicolumn{2}{c|}{ Flows without SIAR constraints } \\
\hline $\begin{array}{c}\text { Absolute mean } \\
\text { difference }\end{array}$ & $\begin{array}{c}\text { Interquantile } \\
\text { range }\end{array}$ & $\begin{array}{c}\text { Absolute mean } \\
\text { difference }\end{array}$ & $\begin{array}{c}90 \% \\
\text { Interquantile } \\
\text { range }\end{array}$ & $\begin{array}{c}\text { Absolute mean } \\
\text { difference }\end{array}$ & $\begin{array}{c}\text { Interquantile } \\
\text { range }\end{array}$ \\
\hline $23 \%$ & $-26 \%$ & $42 \%$ & $-45 \%$ & $12 \%$ & $-15 \%$ \\
\hline
\end{tabular}


Table 5. Comparison of the means and $90 \%$ interquantile (IQ) ranges of the Ecological Network

Analysis indices for each of the models. Negative values for the percent change of $90 \%$ IQ

Range represent a reduction in the range of the Isotope LIM when compared with the

Traditional LIM.

\begin{tabular}{|c|c|c|c|c|c|c|}
\hline \multirow[b]{2}{*}{ ENA Index } & \multicolumn{2}{|c|}{ Traditional LIM } & \multicolumn{2}{|c|}{ Isotope LIM } & \multicolumn{2}{|l|}{ \% Change } \\
\hline & Mean & $90 \%$ IQ Range & Mean & $90 \%$ IQ Range & Absolute Mean Difference & $\begin{array}{c}90 \% \text { IQ } \\
\text { Range }\end{array}$ \\
\hline Total System Throughput & 11,911 & 1,392 & 11,801 & 1,373 & $0.9 \%$ & $-1.4 \%$ \\
\hline Average Path Length & 2.28 & 0.26 & 2.26 & 0.25 & $1.1 \%$ & $-3.8 \%$ \\
\hline Internal Ascendency & 9,486 & 2,372 & 9,325 & 2,369 & $1.7 \%$ & $-0.1 \%$ \\
\hline Internal Development Capacity & 30,733 & 3,860 & 30,047 & 3,770 & $2.2 \%$ & $-2.3 \%$ \\
\hline Ascendency & 19,111 & 2,790 & 18,904 & 2,762 & $1.1 \%$ & $-1.0 \%$ \\
\hline Development Capacity & 36,955 & 4,510 & 36,219 & 4,413 & $2.0 \%$ & $-2.2 \%$ \\
\hline Finn Cycling Index & 0.052 & 0.041 & 0.051 & 0.043 & $0.7 \%$ & $4.9 \%$ \\
\hline Comprehensive Cycling Index & 0.059 & 0.047 & 0.058 & 0.050 & $0.7 \%$ & $6.4 \%$ \\
\hline
\end{tabular}


Figure 1. Overview of Marennes-Oléron Estuary study site, including the intertidal seagrass bed that was modeled. Sampling locations indicated as HFS (High Flat Site) and LFS (Low Flat Site).

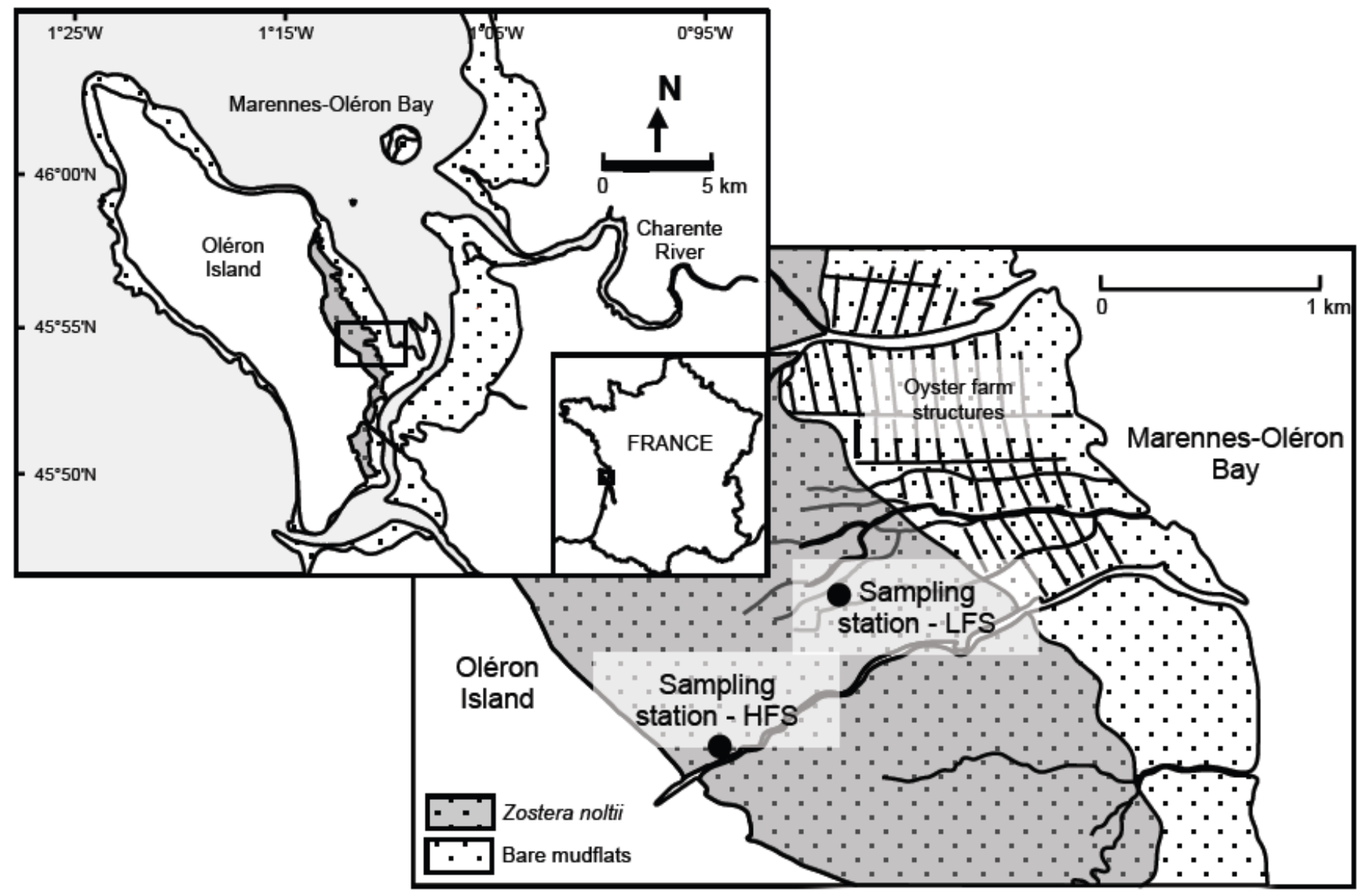


Figure 2. Food web diagram of the Marennes-Oléron intertidal seagrass system, formed using the mean flows from the Isotope LIM. Width of arrows corresponds to relative magnitude of flow in units of $\mathrm{mgC} \mathrm{m} \mathrm{m}^{-2} \mathrm{~d}^{-1}$. Arrows pointing away from center of the web represent respiration and exports from the system. Abbreviations for food web compartments are in Table 1.

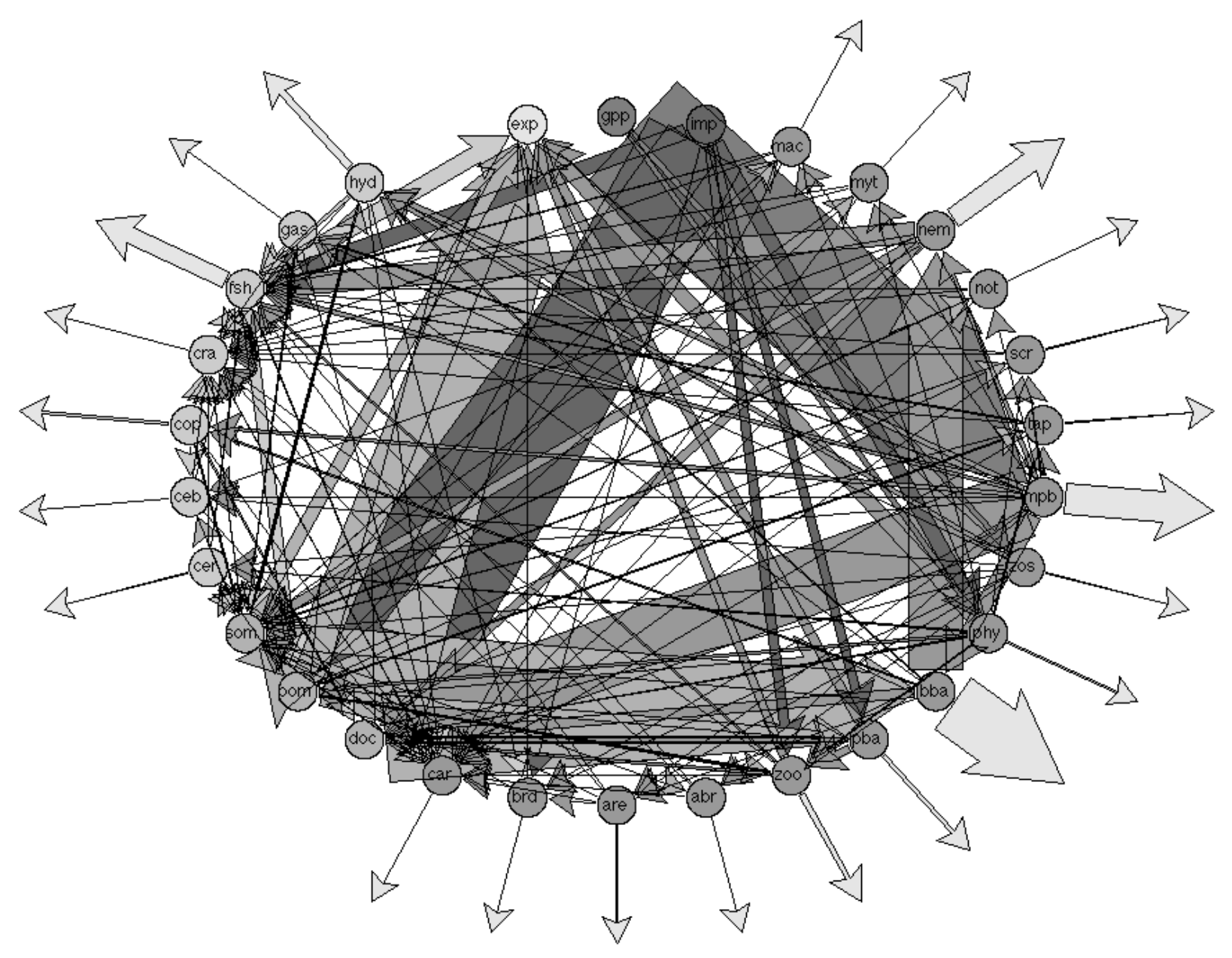


